\title{
HOW MUCH DOES SORTING \\ INCREASE INEQUALITY?
}

Michael Kremer

Working Paper 5566

\author{
NATIONAL BUREAU OF ECONOMIC RESEARCH \\ 1050 Massachusetts Avenue \\ Cambridge, MA 02138 \\ May 1996
}

I am grateful for comments from Ricardo Caballero, Steve Durlauf, Nada Eissa, Glenn Loury, Larry Katz, Casey Mulligan, Paul Romer, Danny Quah, and two anonymous referees. I thank Raghav Kapoor, Amanda Merryman and especially Matt Barmack and Sergei Severinov for outstanding research assistance. Research support was provided by the National Science Foundation grant number SBR9414126, and by the MacArthur Foundation. This paper is part of NBER's research program in Economic Fluctuations and Growth. Any opinions expressed are those of the author and not those of the National Bureau of Economic Research.

(C) 1996 by Michael Kremer. All rights reserved. Short sections of text, not to exceed two paragraphs, may be quoted without explicit permission provided that full credit, including (C) notice, is given to the source. 


\title{
HOW MUCH DOES SORTING \\ INCREASE INEQUALITY?
}

\begin{abstract}
Social commentators from William Julius Wilson to Charles Murray have argued that increased sorting of people into internally homogeneous neighborhoods, schools, and marriages is spurring long-run inequality. Calibration of a formal model suggests that these fears are misplaced. In order to increase the steady-state standard deviation of education by one percent, the correlation between neighbors' education would have to double, or the correlation between spouses' education would have to increase by one-third. In fact, both correlations have declined slightly over the past few decades. Sorting has somewhat more significant effects on intergenerational mobility than on inequality.
\end{abstract}

Michael Kremer

Department of Economics

E52-251c

Massachusetts Institute of Technology

Cambridge, MA 02139

and NBER 
Several influential social commentators have argued that Americans are increasingly sorting into internally homogeneous neighborhoods, schools, workplaces, and marriages, and that this will increase future inequality. William Julius Wilson [1987] contends that black middle-class flight from urban centers leaves inner-city blacks without role models; Robert Reich [1991] argues that a "fortunate fifth" has seceded from close contact with the rest of society; and Herrnstein and Murray [1994] assert that people are sorting more by intelligence, with a "cognitive elite" increasingly living in the same neighborhoods, attending the same schools, working in the same firms, and marrying each other. A series of papers indicate that children may be substantially affected by their neighborhood [Borjas, 1994; Crane, 1991; Corcoran et al., 1989; Cutler and Glaeser, 1995; Case and Katz, 1991]. This suggests that America may be caught in a vicious cycle of increasing sorting and inequality.

When I started this project, I shared these concerns. I now believe that they are based largely on misleading intuition from models in which childrens' outcomes are very strongly influenced by their parents and neighbors. Calibration of a simple model suggests that changes in sorting will have only a small impact on steady-state inequality of characteristics such as education and income.

I assume childrens' inherited characteristics equal a linear combination of their parents' characteristics and their neighbor's characteristics, plus an error term. This implies that greater correlation between spouses or among neighbors in any heritable characteristic will lead to greater inequality of that characteristic in the next generation. It is possible to solve for the steady-state standard deviation of a characteristic as a function of the correlations between spouses' and among neighbors' characteristics.

Data from the Panel Survey of Income Dynamics (PSID) and the 1970 and 1980 Matching Census Extract Data Sets indicate that, on average, a child will obtain an extra 0.38 years of education for each additional year of his or her parents' education. A child will gain an extra 0.13 years of education for each additional year of education in the neighborhood (census tract). Given these parameters, the steady-state standard deviation of educational attainment would increase by approximately $1 \%$--or less than one week--if the correlation between neighbors' education doubled from 0.2 to 0.4 or if the correlation between spouses' education increased from 0.6 to 0.8 .

In fact, these correlations have been stable or declining. The correlation of education among people in the same census tract fell from 0.18 to 0.178 from 1960 to 1990 . The correlation between spouses' education fell from 0.649 to 0.620 between 1940 and 1990 .

The finding that increased sorting has only a minor impact on inequality does not seems to be an artifact of the assumption that children's characteristics are a first-order linear function of parents' and neighbors' characteristics. Estimation of a general Markovian model for intergenerational transmission of education yields similar results. There is little evidence that the moderate observed heritability of education masks a highly inherited latent variable. Even under strong assumptions about the heritability of such a latent variable, the correlation between spouses' education will still have only minor effects on the steady-state standard deviation of education. Although the paper focuses on education, changes in sorting are also unlikely to have significant impacts on inequality of income or occupational status, since these variables have roughly the same heritability as education.

Sorting has a somewhat greater effect on the persistence of educational status across 
generations than on inequality of education. ${ }^{4}$ A doubling of the correlation among neighbors' education would increase the correlation between parents' and childrens' education by 8 percent, from 0.329 to 0.354 . An increase in the correlation between spouses' education from 0.6 to 0.8 would increase the correlation between parents' and childrens' education by 12 percent, from 0.329 to 0.367 . Either of these changes in sorting would produce approximately a 3 percent increase in the steady-state standard deviation of dynastic discounted education. Persistence of economic status among ethnic groups will not be strongly influenced by educational sorting if people draw spouses and neighbors largely from within their own ethnic group.

Benabou [1993a, 1993b], Durlauf [1992, 1994] and Fernandez and Rogerson [1992] examine the transmission of inequality under neighborhood effects. This paper examines similar topics using a modified version of a biological model created by Galton [1889] and Pearson [1896], and generalized by Cavalli-Sforza and Feldman [1981]. Economists such as Becker and Tomes [1979], Becker [1981], Blinder [1973; 1976], and Atkinson [1975], have used related models to examine inheritance. Blinder shows that changes in inheritance rules, or in marital sorting, can have only a slight effect on income distribution through inheritance of physical capital, since inherited wealth accounts for only a small part of inequality. This paper differs from earlier work by allowing the correlation between spouses' characteristics to depend on the variance of characteristics in the population; by incorporating neighborhood effects, by calibrating the model to empirical data on the transmission of education rather than simply the inheritance of financial assets; and by using the model to quantitatively examine contemporary concerns about increased sorting in American society.

The remainder of the paper is organized as follows. Section I models the effect of sorting on inequality using a modified version of the Galton-Pearson model of inheritance. Section II calibrates the model, arguing that sorting into homogeneous households and neighborhoods is likely to have only minor effects on steady-state inequality of education. Section III examines the effect of sorting on the persistence of educational status among families and ethnic groups. Section IV argues that the conclusions are unlikely to change significantly under more general models.

This paper evaluates claims that sorting will increase inequality on their own terms, rather than appealing to incentive responses which are difficult to quantify. However, in the conclusion, I argue that endogenous behavioral responses are likely to further counteract tendencies for sorting to increase inequality. The conclusion also discusses policy implications.

${ }^{4}$ I am grateful to Glen Loury for pointing this out to me. 


\section{The Model}

$\mathrm{t}+1$ is

Suppose that the educational attainment of a member of the ith dynasty in generation

$$
z_{i, t+1}=k_{t+1}+\alpha\left(\frac{z_{i, t}+z_{i, t}}{2}\right)+\beta \frac{\sum_{j=1}^{n} z_{j, t}}{n}+\varepsilon_{i, t+1} \quad 0 \leq \alpha+\beta \leq 1,
$$

where $\alpha$ represents the additional years of education a child will attain given an increase of one year of average parental education, $i^{\prime}$ is the spouse of agent $i, \beta$ represents the additional years of education a child will attain given an increase in average education of one year in the neighborhood, $n$ is the number of neighbors, $z_{j, t}$ is the education of neighbor $j$ at time $t$, and $\varepsilon_{i, t+1}$ is an i.i.d. random shock to educational attainment. Note that $k_{t+1}$ is constant across dynasties, but could vary with time if there is an exogenous time trend in education. This linear, first-order, genderless model should be seen as an illustrative approximation. ${ }^{1}$ In general, $z_{j, t}$ could represent any asset, but for specificity, I will generally refer to $z_{j, t}$ as representing human capital, as measured by years of education. In order to focus on the implications of sorting, I assume that fertility and the transmission of human capital by neighbors and parents are completely inelastic to incentives. All households are assumed to have two children, one boy and one girl. ${ }^{2}$

Squaring both sides of equation (2) and taking expectations shows that the variance of education at time $t+1$ will be an increasing function of $\sigma_{t}^{2}$, the variance of education at time $t$; $\rho_{m}$, the correlation between spouses' education; and $\rho_{n}$, the correlation between neighbors' education. Assuming that $\mathrm{n}$ is large, so that a child's parents can be treated as an insignificant part of the neighborhood,

${ }^{\text {IT }}$ This approximation clearly breaks down for the tails of the distribution, since education is bounded.

${ }^{2}$ Although tendencies for poor households to have more children will clearly affect the steady-state distribution of education, this effect is also likely to be minor [Mare, 1991]. In any case it is not clear that this will interact with changes in the assortativeness of marriage. I therefore abstract from differential fertility in calibrating the effect of changes in marriage patterns on steady state inequality. 


$$
\sigma_{t+1}^{2}=\left[\alpha^{2} \frac{\left(1+\rho_{m}\right)}{2}+\beta^{2} \rho_{n}+2 \alpha \beta \rho_{n}\right] \sigma^{2},+\sigma_{\varepsilon}^{2} .
$$

Solving for the steady state,

$$
\sigma_{\infty}^{2}=\frac{\sigma_{\varepsilon}^{2}}{1-\left[\frac{\alpha^{2}}{2}\left(1+\rho_{m}\right)+\left(\beta^{2}+2 \alpha \beta\right) \rho_{n}\right]} .
$$

It is useful to first consider the effects of sorting in marriage in the special case in which there are no neighborhood effects. This case illustrates principles which carry over to the more general case with both parental and neighborhood effects. If $\beta=0$ or $\rho_{n}=0$, the steady-state variance simplifies to

$$
\sigma_{\infty}^{2}=\frac{\sigma_{\epsilon}^{2}}{1-\alpha^{2}\left(\frac{1+\rho_{m}}{2}\right)}
$$

This paper will generally take $\rho_{\mathrm{m}}$ as exogenous. However, it is worth briefly examining the possibility that greater inequality will lead to a greater correlation between spouses' characteristics, since this may lead to interesting feedback effects. Figure I shows that U.S. states with a higher variance of education also have a higher correlation between spouses' education. $^{3}$ Lam and Schoeni [1993] find that the correlation between spouses's education is 0.77 in Brazil compared to 0.57 in the relatively more equal United States. To understand the possible reasons for this relationship, suppose that people choose spouses of the same observed quality, $q$, where $q_{i, t}$ equals $z_{i, t}$ plus an i.i.d. variable, denoted $\xi_{i, l} \xi_{i, t}$ can be taken to represent a non-heritable characteristic which people value in spouses. ${ }^{4}$

Alternatively, $\xi_{\mathrm{i}, \mathrm{t}}$ could be thought of as noise term that obscures the true quality $\mathrm{z}_{\mathrm{i}, \mathrm{v}}$. Under either interpretation, $\rho_{m}$ will equal $\sigma_{\mathfrak{l}}^{2} /\left(\sigma_{\xi}^{2}+\sigma_{v}^{2}\right)$. The steady-state will be given by the intersection of the functions $\rho_{m}(\sigma)$ and $\sigma\left(\rho_{m}\right)$, as shown in Figure I. A change in matching technology or preferences which reduces $\sigma_{\mu}^{2}$ will create a multiplier effect on steady-state

${ }^{3}$ As will become clear below, this effect is far too big to be explained by the effect of marital sorting on inequality, even if there were no mobility between states.

${ }^{4}$ If there is transferrable utility, people of the same observed quality would match together if there were complementarity between quality of marriage partners. If spouses cannot transfer utility to each other, people of the same quality might match together even if there were no complementarity between spouses' quality [Becker, 1981]. 
inequality. Substituting the formula for $\rho_{m}$ into (4) yields

$$
\begin{gathered}
\sigma_{\infty}^{2}=\frac{\sigma_{\epsilon}^{2}-\sigma_{\xi}^{2}\left(1-\frac{\alpha^{2}}{2}\right)+\sqrt{\left[\sigma_{\epsilon}^{2}-\sigma_{\xi}^{2}\left(1-\frac{\alpha^{2}}{2}\right)\right]^{2}+4 \sigma_{\epsilon}^{2} \sigma_{\xi}^{2}\left(1-\alpha^{2}\right)}}{2\left(1-\alpha^{2}\right)} \quad \alpha<1 ; \\
\frac{2 \sigma_{\epsilon}^{2} \sigma_{\mu}^{2}}{\sigma_{\mu}^{2}-2 \sigma_{\epsilon}^{2}}, \quad \alpha=1, \sigma_{\mu}^{2}>2 \sigma_{\epsilon}^{2} ; \\
\infty, \text { otherwise. }
\end{gathered}
$$

As is apparent from the denominator of (4), the effect of changes in sorting on steadystate-inequality depends critically on $\alpha$. If $\alpha$ equals 1 , the correlation between spouses' assets determines whether inequality increases without bound, or society eventually reaches some steady-state level of inequality. If $\alpha$ is close to 1 , the correlation between spouses' assets will still have a major impact on steady-state inequality. However, if $\alpha$ is small or moderate, the correlation between spouses' assets has only a minor effect on steady-state inequality.

Because they may be responsible for intuition about the effects of sorting on inequality, it is useful to first consider the effect of sorting on steady-state inequality under savings models in which shocks to dynastic wealth are fully transmitted to children, so $\alpha$ equals 1. Let $\mathrm{z}$ represent physical, rather than human capital, and suppose that savings rates

and returns are independent of wealth, and that shocks cannot be perfectly insured. Take $\boldsymbol{\rho}_{m}$ as exogenous. If there is perfect correlation between spouses' wealth, $\mathbf{z}_{\mathrm{i}, t+1}$ will equal $\mathrm{z}_{\mathrm{i}, \mathrm{t}}+$ $\varepsilon_{i, t+1}$. In this case, assets in each dynasty will follow a random walk and the variance of assets among dynasties will grow indefinitely. ${ }^{5}$

However, if the correlation between spouses' assets is bounded away from one, inequality will be bounded. ${ }^{6}$ Rich people will tend to marry less wealthy spouses because most people will be poorer than them, and some of these people will have very large values of $\zeta$, the idiosyncratic variable. This "Marla Maples effect" implies that rich people will on average have children who are poorer than themselves, so the steady-state variance of assets will be finite for $\rho_{m}$ less than one.

${ }^{5}$ If there are decreasing returns to accumulable factors, inequality will eventually be bounded, but only because it will be impossible for the very rich to continue accumulating because of economy-wide diminishing returns.

${ }^{6}$ If $\sigma_{\xi}{ }^{2}$ is small enough relative to $\sigma_{\varepsilon}^{2}$ the correlation between spouses' assets will approach 1 sufficiently quickly that the variance of assets will grow without bound. 
If marriages take place only within countries, there will be a steady-state variance of assets within a country, but the variance of assets among countries will grow indefinitely. The data are consistent with this prediction. Inequality has not grown monotonically within the United States, but the variance of log income (and presumably wealth) among countries has grown over time.

Changes in sorting will have a dramatic effect on steady-state inequality if $\alpha$ is close to 1, but will have a tiny effect if $\alpha$ is moderate. The multiplier effect will also be much larger if $\alpha$ is close to 1 . Table I shows the direct and indirect effects of a reduction in the noise in the marriage process which causes the correlation between spouses' assets to increase from 0.6 to 0.8 .

To see the intuition for why the direct effect is so sensitive to $\alpha$, examine Figure I, or simply note that if $\alpha$ is high, the denominator of equation (4) will be close to zero. The indirect effect of changes in sorting declines much faster than the direct effect as $\alpha$ falls. As discussed in Section II, empirical estimates suggest that in the contemporary United States, $\alpha$ is approximately 0.4 for education and income, which suggests that the direct effect of changes in sorting on inequality is small and the indirect effect is negligible. Given the unimportance of the multiplier effect for realistic values of $\alpha$, I will abstract from it in the remainder of the paper and will focus on the direct effect.

It is straightforward to calculate how big $\alpha$ would need to be for a specified increase in $\rho_{\mathrm{m}}$ to cause specified increase in $\sigma_{\infty}{ }^{7}$. For example, if an increase in $\rho_{\mathrm{m}}$ from 0.6 to 0.8 were to cause a ten percent increase in the standard deviation of education, then by (4),

$$
\frac{\sigma_{\epsilon}}{\sqrt{1-\frac{(1+.8)}{2} \alpha^{2}}}=1.1 \frac{\sigma_{\epsilon}}{\sqrt{1-\frac{(1+.6)}{2} \alpha^{2}}} .
$$

Solving this equation implies that $\alpha$ would have to equal 0.84 .

The relationship between sorting and the steady-state standard deviation of human capital is qualitatively similar if $\beta$ is greater than zero, so childrens' education is affected by average education in the neighborhood. Increases in sorting will always increase steady-state inequality, but this effect will only be strong if $\alpha+\beta$ is close to 1 , and $\rho_{\mathrm{m}}$ and $\rho_{\mathrm{n}}$ are large, so that the denominator of (3) is close to zero. Even if $\alpha+\beta$ is close to 1 , the steady-state variance is only moderately sensitive to the correlation between spouses' assets if $\rho_{m}$ and $\rho_{n}$ are small.

Equation (3) indicates that the effects of simultaneous increases in sorting in marriage and neighborhoods are greater than the sum of the effects of separate increases. However, as discussed below, this complementarity between sorting in marriage and neighborhoods is relatively minor for realistic values of $\alpha$ and $\beta$.

${ }^{7} \mathrm{I}$ am grateful to a referee for the derivation below. 


\section{Calibration}

This section calibrates the model to the distribution of human capital in the United States. Using data from the PSID, and from the Matching Census Extract Data sets, I find that $\alpha$, the parental effect, is approximately 0.38 , and that an upper bound on $\beta$, the neighborhood effect, is 0.13 . Given these parameters, increases in sorting by education are likely to have a minor impact on the steady-state standard deviation of education.

I focus on education, rather than income, because spouses' income is endogenous to marriage, and sorting is only well-defined for variables which are exogenous to marriages and neighborhoods. Moreover, as Solon [1992], and Zimmerman [1992], have shown, measurement error or fluctuations in income will bias estimates of the effect of parental and neighborhood income on childrens' income. Of course, there may be measurement error in education as well, to the extent that years of education do not accurately represent the correct theoretical concept of human capital, but it is likely to be smaller than that for income. For some purposes, education may in fact be a better indicator of socio-economic status than income.

Table II reports summary statistics on childrens' and parents' education from the first 21 waves of the PSID (up through the 1988 interview year). Only children over twenty-five years old in 1988 were included in the sample, to avoid including children who had not yet completed their education. People with any post-graduate education were classified as having 17 years of schooling. In order to use self-reported data from both parents and children, I used split-offs from the original PSID sample. This means that the sample is not a random sample of the population because it misses the replenishments to the PSID to replace people lost to attrition.

Data on the average education in the census tract in which the child grew up were taken from taken from the 1970 census. Census tracts typically comprise five thousand people, so this represents a fairly small area. The neighbors' education was calculated as the average education of males over 25 in the census tract in which the child resided between 1968 and 1975, weighted by the number or years the child spent in the census tract.

People were excluded from the sample if information was not available on the census tract in which they grew up, or if self-reported data on both parents was not available. Children who grew up in single parent households were included, as long as data was available on both parents. Similar results were obtained for a larger sample, including all those for whom child-reported measure of parental education were available.

Column (1) of Table III shows the baseline specification. The parental effect is estimated to be 0.379 , the neighborhood effect is estimated to be 0.127 , and the standard deviation of the shock to education is estimated to be 1.74 years. The estimated neighborhood effect is large: living in an educated neighborhood increases the expected education for one's children two- thirds as much as marrying an educated spouse. As discussed below, the coefficient on parents' characteristics is likely to be biased downwards and the coefficient on neighborhood characteristics is likely to be biased upwards.

The remaining columns of Table III test how well this linear, genderless model approximates reality. Column (3) distinguishes between mothers' and fathers' effects on their childrens' education. An F-test cannot reject the null hypothesis of equal effects of mothers' 
and fathers' education. A previous version of this paper obtained similar results using a more general, (but much messier), model that distinguished between fathers and mothers, and between sons and daughters.

Column (4) of Table III checks how well the linear model approximates the process of intergenerational transmission by adding quadratic and interaction terms to the regression. Although the difference in adjusted $\mathrm{R}^{2}$ between the models is small, an F-test rejects linearity. Section III estimates a more general Markovian model of intergenerational transmission that does not impose linearity.

Given the estimated parameters, education is remarkably insensitive to the correlation between spouses' or among neighbors' education. The standard deviation of steady-state education would increase from 1.87 to 1.89 years -0.8 percent - if the correlation between spouses' education increased from 0.6 to 0.8 . It would increase 1.3 percent if the correlation between neighbors' education doubled from 0.2 to 0.4 . Assuming a 180 day school year, these hypothetical increases in segregation would increase the standard deviation of education by about a week. Simultaneous increases in sorting in marriage and in neighborhoods of these magnitudes would increase the steady-state standard deviation of years of education to $2.2 \%$, slightly more than the sum of the individual effects. Although these changes are small, they happen relatively quickly: the standard deviation of education will increase 85 percent of the way to its steady-state value after in single generation following the increase in sorting.

Note that sorting by education has been quite stable historically, so that the changes hypothesized above are extreme. In 1960, the correlation between the education of people in the same census tract was $0.180 .^{8}$ In 1990 , it had fallen to 0.178 . In a sample of couples from the public use microsample of the 1940 census in which the husband was between the ages of 30 and 45, the correlation of years of education between spouses was 0.649 . By 1980, it had fallen to 0.633 , and by 1990 , it had fallen to $0.620 .^{9}$ (Note, however, that Mare [1991] and Kalmijn [1991] find slight increases in assortativeness of marriage using a measure of sorting based on the likelihood of crossing educational barriers, such as the high school graduate/some college barrier. Kremer and Maskin [1995] discuss the justification for correlation as a measure of sorting. Whichever measure is used, the overall impression is of stability in sorting patterns over long periods.)

Measurement error in parents' education will bias the estimated $\alpha$ downwards. Ashenfelter and Krueger [1994] estimate that 8 to 12 percent of measured variance in schooling is due to error, and they cite previous estimates by Siegel and Hodge [1968] and Bielby [1977] that between 13 and 20 percent of the variance of schooling is due to

\footnotetext{
${ }^{8}$ This may be due in part to equalization of incomes among regions of the country during the period.

${ }^{9}$ Given that men and women have different educational distributions, and that these distributions have mass points, the maximum feasible correlation between spouses' education is less than one. For example, in 1990, the maximum feasible correlation between spouses' education was 0.96 . There was a slight decline over the period in the ratio of the actual correlation to the maximum feasible correlation between spouses' education.
} 
measurement error. Measurement error in parents' education will bias $\beta$ upwards to the extent that parents' education is correlated with neighbors' education. $\beta$ will also be overestimated if parents who value education tend to live in educated neighborhoods. Under the extreme assumptions that twenty percent of the variance in parents' characteristics were measurement error, and that none of the effect of parents' education was picked up by the neighborhood, $\alpha$ would be $0.38 * 5 / 4=0.47$ and $\beta$ would be 0.13 . In this case, an increase in $\rho_{m}$ from 0.6 to 0.8 or in $\rho_{n}$ from 0.2 to 0.4 would increase the steady-state standard deviation of education by approximately 1.5 percent. Even if $\alpha$ were 0.6 and $\beta$ were 0.13 , an increase in $\rho_{\mathrm{n}}$ from 0.6 to 0.8 would increase the steady-state standard deviation of education by only 2.8 percent. A doubling of $\rho_{\mathrm{m}}$ from 0.2 to 0.4 would have a slightly smaller effect.

Substituting the estimated parameters into (4) implies that the steady-state standard deviation of education will be 1.87 years, which is less than the 2.11 year standard deviation of education among children in the parents' generation. ${ }^{10}$ The model's implication that inequality is above its steady-state value is consistent with the fact that the standard deviation has been dropping over the past generation. ${ }^{11}$ The variance of education may have been greater in previous generations due to greater regional and racial variation in education spending, and more limited public support of higher education.

Results are likely to be similar for characteristics other than education. The heritability of income is approximately 0.4, according to Solon [1992] and Zimmerman [1992]. Blau and Duncan [1967] find similar correlations for occupational status. Herrnstein and Murray [1994] claim that intelligence is about 60 percent heritable and issue dire warnings about the effects of alleged recent increases in assortative mating by intelligence. If Herrnstein and Murray's estimates of the heritability of intelligence are accepted at face value, then increased correlation of spouses' intelligence is likely to have a minor impact on the steady-state variance of intelligence under the model. (However, this model may not be appropriate for examining the genetic transmission that Herrnstein and Murray believe drives intergenerational correlation of intelligence.)

The main exception to findings of heritability in this range or below is Mulligan [1995], who finds the intergenerational correlation of consumption is approximately 0.8 when

${ }^{10}$ Note that this is the standard deviation of years of education for a sample of people young enough to have parents in the PSID. The standard deviation is thus much smaller than it would be in a sample containing both recent and older cohorts.

"There is some evidence that $\alpha$ may have been greater in the past: regressions of fathers' education on fathers' reports of grandfathers' education yield an $\alpha$ of 0.56 . This is not merely an artifact of reduced differences between men and women; the standard deviation of education among fathers in the sample is 3.49 years, while the standard deviation of education among sons is 2.15 ; similarly, the standard deviation of education among mothers is 2.62 , while the standard deviation of education among daughters is 2.06 . On the other hand, Blau and Duncan [1967], find that the correlation of occupational status on fathers and sons in 1964 was 0.4 , indicating that there has been little change in father-son correlation of economic status. 
parental income is used as an instrument for parental consumption. However, if parental income influences children's consumption directly, IV techniques may lead to significant upward biases in estimates of heritability. It is not clear how to reconcile such a high correlation in consumption with the lower correlations in income documented by Solon [1992] and Zimmerman [1992]. In any case, if $\alpha=0.8$ and $\beta=0$, assortative marriage begins to play a somewhat important role: an increase in $\rho_{m}$ from 0.6 to 0.8 will increase the standard deviation of consumption by 7.3 percent. A fuller analysis would examine the case of multiple, correlated, heritable characteristics, as proposed by Goldberger [1979].

\section{Sorting and Persistence of Inequality}

Although changes in sorting have only a small impact on inequality, they have a somewhat more significant impact on the intergenerational correlation of education. The steady-state correlation between the educational attainment of a parent and his or her child is

$$
\operatorname{corr}_{\infty}\left(z_{i, r}, z_{i t+1}\right)=\frac{\alpha\left(1+\rho_{m}\right)}{2}+\beta \rho_{n} .
$$

A doubling of $\rho_{\mathrm{n}}$ from 0.2 to 0.4 will increase the intergenerational correlation of education by 8 percent, from 0.329 to 0.354 . An increase in $\rho_{m}$ from 0.6 to 0.8 will increase the intergenerational correlation by 12 percent, from 0.329 to 0.367 . (Recall, however, that these hypothesized changes in $\rho_{m}$ and $\rho_{n}$ are many times greater than the changes which have been experienced historically.)

Since sorting increases the intergenerational correlation of education, inequality among dynasties will be more sensitive to sorting than inequality among individuals. Define "discounted dynastic education" as

$$
D_{i, t}=E \sum_{t=1}^{\infty} \delta^{t} z_{i, t}
$$

where $\delta$ is the discount rate..$^{12}$ Assuming that the population is in steady-state,

$$
D_{i, t}=\sum_{t=1}^{\infty} \delta^{t}\left[\mu-\left(\alpha \frac{1+\rho_{m}}{2}+\beta \rho_{n}\right)^{t}\left(\mu-z_{i, t}\right)\right],
$$

where $\mu$ denotes the mean level of education. This implies that the steady-state variance of

\footnotetext{
${ }^{12}$ Obviously, this concept is a bit ad hoc. On the other hand, if wages are approximately exponential in education, and utility is $\log$, it may not be a terrible welfare indicator.
} 
discounted dynastic education is

$$
\sigma_{D}^{2}=\frac{\sigma_{\infty}^{2}}{\left[1-\delta\left(\alpha \frac{1+\rho_{m}}{2}+\beta \rho_{n}\right)\right]^{2}} .
$$

Assuming an intergenerational discount rate of 0.5 , an increase in $\rho_{\mathrm{m}}$ from 0.6 to 0.8 would increase the standard deviation of discounted dynastic education by 3.4 percent, and an increase in $\rho_{\mathrm{n}}$ from 0.2 to 0.4 would increase it by 3.1 percent.

Under the model, if spouses and neighbors are chosen with regard to education but not ethnicity, ethnic groups will converge to the mean level of education at a rate corresponding to the intergenerational correlation of education. Sorting will therefore slow convergence among ethnic groups. This effect will be exacerbated if childrens' education is influenced by the "ethnic capital" of their group, as in Borjas [1994]. However, if there is substantial sorting on purely ethnic grounds, sorting by education will only have a minor impact on the rate of convergence among ethnic groups. Suppose

To see this, consider a model with both neighborhood effects and ethnic group effects.

$$
z_{i, t+1}=k+\alpha\left(\frac{z_{i, t}+z_{i^{\prime}, t}}{2}\right)+\beta \sum_{j=1}^{n} \frac{z_{j, t}}{n}+\gamma z_{g, t}+\epsilon_{t},
$$

where $\gamma$ measures the strength of ethnic transmission, and $z_{g, t}$ is the human capital of ethnic group $\mathrm{g}$ at time $\mathrm{t}$. (I assume that a child of parents from two different ethnic groups has equal probability of becoming a member of either.) Suppose that a randomly drawn fraction of each ethnic group $w_{m}$ marries within the ethnic group, that a fraction $w_{n}$ lives in an ethnic neighborhood, and that the remainder sort by education alone. Given the linearity of the model, one can calculate average education of a group in period $t+1$ as if a fraction $w_{m}+(1$ $\left.-w_{m}\right) \rho_{m}$ of the ethnic group marries a spouse with the average education of people in the ethnic group, and a fraction $\left(1-w_{m}\right)\left(1-\rho_{m}\right)$ marries a spouse with the average education in the society as a whole. Thus

$$
z_{g, t+1}=k+\theta z_{g, t}+[\alpha+\beta+\gamma-\theta] \mu_{t}
$$

where $\mu_{1}$ denotes the average education of all members of the population, and $\theta$, the persistence of differentials among groups, equals $\alpha+\beta+\gamma-\left(1-w_{m}\right)\left(1-\rho_{m}\right) \alpha / 2-\left(1-w_{n}\right)$ $\left(1-\rho_{\mathrm{n}}\right) \beta$. Assuming that $\alpha+\beta+\gamma<1$, all groups will converge to the same steady-state independently of sorting, but they will approach the steady-state more quickly if more members of the group match with spouses and neighbors from outside the group, and if more of these people have spouses and neighbors with the average education in the population as a whole.

Changes in sorting by education will have only have a minor impact on $\theta$, persistence 
of inequality among ethnic groups, if groups sort strongly by ethnicity - precisely the circumstances under which disparities among ethnic groups are likely to have the most social significance. For example, if $w_{m}=0.7$, and $w_{n}=0.5$, then the increases in sorting in marriage and neighborhoods described above would increase $\theta$ from 0.432 to 0.444 and 0.445 respectively. ${ }^{13}$

There has been a debate about whether social policy should focus on reducing sorting by race and ethnicity, or sorting by socio-economic status. The analysis in previous sections implies sorting by education will have little effect on inequality among individuals. The analysis in this section suggests that if groups sort highly by ethnicity, reducing sorting by ethnicity is likely to have a larger effect on disparities between ethnic groups than reducing sorting by education.

\section{Extensions}

The previous sections assumed education was transmitted by a first-order linear process. Theoretically, sorting could have a bigger impact on inequality if education were transmitted through a non-linear process, or if there were a highly heritable latent variable which influenced education. This section argues that an initial examination of the data does not suggest that relaxing the assumptions of the model will significantly change the conclusion that sorting has minor effects on steady-state inequality.

In order to examine the effect of marital sorting on inequality in a more general Markovian context, I divided the population into six education categories: 1) elementary school and below, 2) some high school, 3) high school, 4) some college, 5) college, and 6) more than college. I then estimated the probability that the child will be in each category conditional on the category of each parent. ${ }^{14}$ Given the estimated Markovian transition matrix, it is possible to solve for the steady-state distribution of education that would obtain if a proportion $\Psi$ of the population chose spouses with the same education, and a proportion 1 $\Psi$ chose spouses randomly. ${ }^{15}$ As $\Psi$ increases from 0.6 to 0.8 , the steady-state standard deviation of education increases by approximately 1.1 percent.

A similar transition matrix was constructed to examine the effect of sorting by neighborhood. I divided the population into four quartiles, corresponding to the quartiles of

\footnotetext{
${ }^{13}$ In a regression of childrens' education on parents' education, neighbors' education, and the average education of their ethnic group, ethnic education is insignificant (and negative), so I assume $\gamma=0$.

${ }^{14}$ Scarcity of data made it impossible to distinguish the effects of mothers' and fathers' education separately.

${ }^{15}$ One weakness of this approach is that it does not take into account that those who do not match with others of the same education are likely to match with people of similar education. Thus, this procedure gives equal weight to all the off-diagonal cells in the transition matrix, rather than weighting the cells near the diagonal more heavily than those far from the diagonal.
} 
the distribution of education by neighborhood, and then constructed a transition matrix. In analyzing the effect of sorting by neighborhood, I assumed that the correlation between spouses' education was 0.6 , and that parents' education could be summarized by the average education of the parents. The analysis indicates that an increase in $\rho_{n}$ from 0.2 to 0.4 leads to an increase in the steady-state standard deviation of education of approximately $3 / 10$ ths of one percent.

Scarcity of data made it impossible to use finer categories or to simultaneously allow for non-linearities in parental and neighborhood transmission. For example, there are too few couples in which the mother has a college education, the father has an elementary school education, and the typical neighbor had a high school education to accurately estimate the distribution of education for children with this background.

Under Markovian models, in which childrens' education is a non-linear function of parents' and neighbors' education, average steady-state education will typically depend on the pattern of matching. Under the estimated Markovian transition matrices, average steady-state education increases slightly with the correlation between neighbors' education, but falls with the correlation between spouses' education. ${ }^{16}$ Average steady-state education would fall 1.4 percent in response to an increase in the correlation between spouses' education from 0.6 to 0.8. Recall that if utility is transferable, an efficient marriage pattern will be chosen, so people will consider this cost of sorting in choosing spouses. However, if consumption within the household is joint, it may be difficult for less educated people to compensate more educated people for marrying them. In any case, as discussed in the conclusion, the implication that the average level of education will be reduced by increased correlation between spouses' education is likely to be overturned by endogenizing $\alpha$, the heritability of education.

Besides its assumption of linearity, another restrictive assumption of the model is that education is transmitted by a first-order process - i.e., that childrens' educations is influenced only by parents' education. Theoretically, moderate heritability of education could potentially mask stronger heritability of an underlying latent variable. To see this, suppose that $z$ is a persistent latent variable influencing education, and that education, denoted $y$, equals $z+\theta$, where $\theta$ is i.i.d. with mean zero and variance $\sigma_{\theta}{ }^{2}$. Assume that the correlation between spouses' latent variables is the same as the correlation between their observed years of education $^{17}$, and that there are no neighborhood effects. ${ }^{18}$

${ }^{16}$ Sorting has similar effects on average predicted income given education, which is itself a non-linear function of education.

17 To the extent that people care about their spouse's education, they will match on the basis of education, rather than the latent variable. However, people with high values of the latent variable will be considered more desirable partners because they will typically have more educated children. Moreover, people may have some information about the latent variable by observing relatives. 
Under this model, the estimate of $\alpha$ will be subject to attenuation bias, as in errors-invariables models. The estimated heritability of education will be

Note that $\sigma_{z}^{2}+\sigma_{\theta}^{2}=\sigma_{y}^{2}$. The probability limit of the estimated standard error will be

$$
\begin{gathered}
\text { plim } \hat{\sigma}_{\epsilon}^{2}=(\alpha-\hat{\alpha})^{2} \sigma_{z, t-1}^{2}\left(\frac{1+\rho}{2}\right)+\sigma_{\epsilon}^{2}+\sigma_{\theta}^{2}+\hat{\alpha}^{2} \sigma_{\theta}^{2}\left(\frac{1+\rho}{2}\right) . \\
p l i m \quad \hat{\alpha}=\frac{\sigma_{Z}^{2}}{\sigma_{\theta}^{2}+\sigma_{Z}^{2}} \alpha .
\end{gathered}
$$

Under the latent variable model, the steady-state variance of education will be

$$
\sigma_{\infty}^{2}=\frac{2 \sigma_{\epsilon}^{2}}{2-\alpha^{2}(1+\rho)}+\sigma_{\theta}^{2} .
$$

On the one hand, greater values of $\alpha$ imply that steady-state inequality of the latent variable will be more sensitive to the correlation between spouses' education. On the other hand, for a given $\alpha$, a greater $\alpha$ implies a greater variance of $\theta$, the i.i.d. variable influencing education. The greater $\sigma_{\theta}{ }^{2}$, the less sensitive inequality will be to the correlation between spouses' education.

Instrumental variables estimation using grandparents' education as an instrument for parents' education suggests that $\alpha$ is approximately 0.44 . When neighbors' education is put in the regression, the IV estimate of $\alpha$ increases to 0.58 . Neighbors' education is insignificant in the regression; the change in the coefficient is due to the loss of approximately $30 \%$ percent of the data in the sample for which data is available on neighbors. This suggests that the 0.44 for estimate may be preferable, but both estimates should be treated with caution. If grandparents directly contribute to their grandchildren' education, the IV estimate will be biased upwards. Equations (13) through (15) imply that if $\alpha$ is 0.44 , an increase in $\rho_{m}$ from 0.6 to 0.8 will increase $\sigma_{\infty}$ by $0.9 \%$, compared to $0.8 \%$ under the baseline model. This change in sorting would increase $\sigma_{\infty}$ by $1 \%$ if $\alpha$ was 0.6 , but by only $0.7 \%$ if $\alpha$ was 0.7 , since this implies a large $\sigma_{\theta}^{2}$.

These results with more complicated models should be considered provisional. It is possible that sorting has stronger effects at the extreme tails of the distribution. The Markov analysis may not have been fine enough to determine the effects of segregation on segregation in inner city ghettos, or among Native Americans in South Dakota. Theoretically, the estimation of more complex latent variable models could yield larger effects of sorting on inequality. However, initial efforts in these directions suggest that the results of previous

\footnotetext{
${ }^{18}$ Neighborhood effects are statistically insignificant in the estimated latent variable model.
} 
sections are fairly robust.

\section{Conclusion}

Authors from a variety of political perspectives have argued that America is becoming caught in a tide of increasing inequality and segregation. The data reviewed in this paper cast doubt on the view that Americans are sorting more than before, and the calibration suggests that increased correlation between spouses or among neighbors' is likely to have a minor effect on inequality of moderately heritable characteristics. As shown in Table IV, even dramatic increases in sorting in either marriages or neighborhoods would increase the standard deviation of education by only 1 percent, or approximately one week. Increased sorting is likely to have a moderate impact on the intergenerational correlation of education. While other models might also fit the data but yield different long-run predictions, there is no reason to presume these more complicated models would suggest a larger, rather than smaller, effect of segregation on long-run inequality.

In fact, the analysis in this paper may overestimate the effect of sorting on inequality, since it takes $\alpha$, the effect of parents' education on their children's education, as exogenous to sorting patterns. Reductions in the cost of sorting are likely to raise the private return on educational investments closer to the social return. They may also reduce incentives for parents to adjust their consumption to the mean to smooth consumption across generations.

Becker [1981] argues that parents have greater incentive to invest in childrens' education if this increases the child's chance of marrying a desirable spouse. Imperfectly assortative marriage can be seen as a tax on parents' investments in their children, with the proceeds going to their children-in-law. If $\rho_{\mathrm{m}}=0.6$, average education of a child and his or her spouse will increase by 0.8 years for every extra year of education the child's parents provide. If $\rho_{\mathrm{m}}$ rises by $1 / 3$, to 0.8 , average education of a child and his or her spouse will increase by 0.9 years for every extra year of education the child's parents provide. It seems likely that this twelve and a half percent increase in the return to educational investment would increase investment in education by more than enough to offset the approximately one percent decline in education from increased marital sorting in the estimated Markovian model. ${ }^{19}$

If improvements in the matching technology lead parents to increase investment in education, and thus increase $\alpha$, both the variance and the average level of education will increase [Becker 1981]. In situations in which the average level of education changes, the coefficient of variation, $\sigma / \mu$, provides a better measure of inequality than the standard deviation of education. Under this model, with its additive error term, increases in $\alpha$ will reduce the coefficient of variation, but in general, there is no reason to presume that increases in parental investment in children will affect the coefficient of variation one way or the other.

${ }^{19}$ To the extent that imperfectly assortative marriage arises not because of informational problems, but because people also value other noninherited characteristics, reduced variance in these non-inherited characteristics will not necessarily lead parents to invest more in education. 
Improved matching will also reduce incentives for consumption smoothing across generations, and this will make the long-run distribution of assets more equal. This is because improvements in matching technology will cause poor people to expect worse marriages for their children, and rich people to expect better marriages for their children. The consequent reduction in the desire for consumption smoothing across generations will cause poor people to save more and rich people to save less. Thus the direct effect of increased sorting on inequality may be partially counteracted by behavioral response.

Sorting by academic ability in schools or by skill in workplaces may have larger effects on inequality than sorting by parental characteristics, since an individual's future characteristics are presumably more highly correlated with his or her current characteristics than with his or her parents' characteristics. Ironically, this suggests that the form of sorting which is seen as least objectionable from an egalitarian point of view may be most important in increasing inequality. There is some evidence that sorting by these characteristics is increasing. Kremer and Maskin [1994] present evidence that sorting in workplaces has increased. Hernstein and Murray present [1994] anecdotal, but fairly convincing, evidence of increased sorting by academic ability in higher education.

Public policy toward sorting may depend on many things other than its effect on inequality. Increased sorting may make inequalities more persistent, exacerbate political conflict, or widen social and cultural gaps within the population. On the other hand, under some conditions, decentralized agents may choose efficient sorting patterns, as Becker has argued. People may sort according to their preferences for public goods, for example. In any case, sorting is often difficult and expensive to change through policy, as exemplified by the history of school busing. Investing directly in the poor may have a greater effect on inequality and poverty than re-shuffling the rich and the poor to be nearer each other. 


\section{References}

Ashenfelter, Orley and Alan Krueger, "Estimates of the Economic Return to Schooling from a New Sample of Twins," The American Economics Review, December 1994, 1157-1173.

Arnott, Richard and John Rowse, "Peer Group Effects and Educational Attainment," Journal of Public Economics, XXXII (1987), 287-305.

Atkinson, A.B., The Economics of Inequality, (Oxford: Clarendon Press, 1975).

Blau, Peter M. and Otis Dudly Duncan, The American Occupational Structure, (New York: Wiley, 1967).

Becker, Gary, A Treatise on the Family (Cambridge, MA: Harvard University Press, 1981).

Becker, Gary S. and N. Tomes, "An Equilibrium Theory of the Distribution of Income and Intergenerational Mobility," Journal of Political Economy, LXXXVII (1979), 1153-1189.

Benabou, Roland, "Heterogeneity, Stratification and Growth," Forthcoming, American Economic Review.

Benabou, Roland, "Workings of a City: Location, Education, and Production," Quarterly Journal of Economics, CVIII (1993b), 619-652.

Bielby, William; Hauser, Robert and David Featherman. "Response Errors of Non-Black Males in Models of the Stratification Process," in D. L. Aigner and A. S. Goldberger, eds., Latent Variables in Socioeconomic Models. Amsterdam: North Holland, 1977, pp. 227-51.

Blinder, Alan S., "A Model of Inherited Wealth," Quarterly Journal of Economics, LXXXVII (1973), 608-626.

Blinder, Alan S., "A Micro Stimulation Model of the Size Distribution of Income," The Journal of Economics and Business, XXVII (1974), 11-9.

Blinder, Alan S., "Inequality and Mobility in the Distribution of Wealth," Kyklos, XXIX (1976), 607-638.

Borjas, George, "Ethnicity, Neighborhoods, and Human Capital Externalities," American Economic Review, LXXXV (1995), 365-90.

Borjas, George, "Ethnic Capital and Intergenerational Mobility," Quarterly Journal of Economics, CVII (1992), 123-150.

Case, Anne C. and Lawrence F. Katz, "The Company You Keep: The Effects of Family and 
Neighborhood on Disadvantaged Youths," NBER Working_Paper No. 3705, (1991).

Cavalli-Sforza, Luigi Luca, and Martin Feldman,_Cultural Transmission and Evolution: $\underline{A}$ Quantitative Approach, (Princeton, NJ: Princeton University Press, 1981).

Cooper, Suzanne J., Steven N. Durlauf, and Paul A. Johnson, [1993], "On the Evolution of Economic Status Across Generations," Proceedings of the Business and Economic Statistics Section, American Statistical Association, 50-8.

Corcoran, Mary, Roger Gordon, Deborah Laren and Gary Solon, "Effects of Family and Community Background on Men's Economic Status," NBER Working_Paper No. 2896. (1989).

Crane, Jonathan, "The Epidemic Theory of Ghettos and Neighborhood Effects on Dropping Out and Teenage Childbearing," American Journal of Sociology, ICVI (1991), 1226- 59.

Crow, James F. and Motoo Kimura, An Introduction to Population Genetics Theory (New York: Harper and Row, 1970).

Cutler, David and Edward Glaeser, "Are Ghettos Good or Bad?" Unpublished Manuscript, 1995.

Durlauf, Steven N., "On the Evolution of Economic Status Across Generations," Social Systems Research Institute, 422 University of Wisconsin Madison,

Durlauf, Steven, "A Theory of Persistent Income Inequality," NBER Working Paper No. 4056, (1992).

Durlauf, Steven N., "Neighborhood Feedbacks, Endogenous Stratification, and Income Equality," NBER (1994). University of Wisconsin Madison.

Fernandez, Raquel and Richard Rogerson, "Income Distribution, Communities and the Quality of Public Education: A Policy Analysis," NBER Working Paper No.4158, (1992).

Goldberger, Art, "Family Data Analysis: Assortment, Selection, and Transmission," University of Wisconsin, Unpublished, 1979.

Goldin, Claudia, "The Meaning of College in the Lives of American Women," NBER Working_Paper No 4099, (1992).

Herrnstein, Richard J. and Charles Murray, The Bell Curve: Intelligence and Class Structure in American Life (New York: The Free Press, 1994).

Hill, Martha S. and Greg J. Duncan, "Parental Family Income and the Socioeconomic 
Attainment of Children," _Social Science Research, XVI (1987), 39-73.

Kalmijn, Matthijs, "Status Homogamy in the United States," American Journal of Sociology, ICVII (1991a), 496-523.

Kalmijn, Matthijs, "Shifting Boundaries: Trends In Religious And Educational Homogamy," American Sociological Review, LVI (1991b), 786-800.

Kalmijn, Matthijs, "Trends in Black/White Intermarriage," Social Forces. LVVII (1993), 119146.

Kremer, Michael, "The O-Ring Theory of Economic Development," Quarterly Journal of Economics, CVIII (1993), 551-575.

Kremer, Michael and Eric Maskin, "Segregation by Skill and the Rise in Inequality," MIT, unpublished, 1995.

Lam, David, "Marriage Markets and Assortative Mating with Household Public Goods:

Theoretical Results and Empirical Implications," The Journal of Human Resources, XXIII (1995), 462-487.

Lam, David and Robert Schoeni, "Family Ties and Labor Markets in the United States and Brazil," Working Paper, 1993.

Lam, David, and Robert Schoeni, "Effects of Family Background on Earnings and Returns to Schooling: Evidence from Brazil," Journal of Political Economy, CI (1993), 710-740.

Manski, C., "Identification Problems in the Social Sciences," Sociological Methodology, vol. 23, (Cambridge: Basil Blackwell, 1993a)

Manski, C. "Identification of Endogenous Social Effects: The Reflection Problem,"-Review of Economic Studies, 60 (1993b), 531-542.

Mare, Robert D., "Five Decades of Educational Assortative Mating," American Sociological Review, LVI (1991), 15-32.

Menchik, Paul L., "Inter-generational Transmission of Inequality: An Empirical Study of Wealth Mobility," Economica XXXXVI(1979), 349-62.

Miguel, Edward A., "Notes on Assortative Matching," MIT, unpublished, 1995.

Mulligan, Casey B., "On Intergenerational Altruism, Fertility, and the Persistence of Economic Status," University of Chicago, Ph. D thesis, August 1993. 
Mulligan, Casey B., "Economic Biological Approaches to Inheritance: Some Evidence," University of Chicago, unpublished??, October 1995.

Murphy, Kevin and Finis Welch, "Occupational Change and the Demand for Skill: 19401990," American Economic Review, LXXXVIII (1993), 122-126.

Reich, Robert, "Secession of the Successful," New York Times Magazine, (20 Jan 1991), 1617.

Rockwell, Richard C., "Historical Trends and Variations in Educational Homogamy," Journal of Marriage and the Family, XXXVIII (1976), 83-95.

Siegel, Paul and Robert Hodge. "A Causal Approach to the Study of Measurement Error," in Hubert Blalock and Ann Blalock eds., Methodology in Social Science Research. New York: McGraw-Hill, 1986, pp. 28-59.

Solon, Gary, "Intergenerational Income Mobility in the United States," American Economic Review, LXXXII(1992), 393-408.

Wilson, William Julius, The Truly Disadvantaged: The Inner City the Underclass, and Public Policy, (Chicago, IL: University of Chicago Press, 1987).

Zimmerman, David J., "Regression Toward Mediocrity in Economic Stature," American Economic Review, Vol. 82, No. 3, June 1992, pp. 409-429. 
Table I: Direct and Indirect Effect of Increasing $\rho_{\mathrm{m}}$ from 0.6 to 0.8

\begin{tabular}{||c|c|c|c||}
\hline$\alpha$ & $\begin{array}{c}\% \text { direct increase } \\
\text { in } \sigma_{\infty}\end{array}$ & $\begin{array}{c}\rho_{\mathrm{m}} \text { after multiplier } \\
\text { effect }\end{array}$ & $\begin{array}{c}\% \text { indirect increase } \\
\text { in } \sigma_{\infty}\end{array}$ \\
\hline \hline 0.9 & 14.0 & 0.850 & 4.0 \\
\hline 0.8 & 1.0 & 0.825 & 1.0 \\
\hline 0.6 & 2.7 & 0.809 & 0.11 \\
\hline 0.4 & 1.0 & 0.803 & 0.01 \\
\hline
\end{tabular}


Table II: Years of Education

\begin{tabular}{||l||r|r|r|}
\hline Years of Schooling & \multicolumn{1}{|c|}{ Father } & Mother & Children \\
\hline 2 & $0.38 \%$ & $0 \%$ & $0 \%$ \\
3 & $1.63 \%$ & $.46 \%$ & $0.04 \%$ \\
4 & $2.63 \%$ & $.21 \%$ & $0 \%$ \\
5 & $2.42 \%$ & $1.25 \%$ & $0 \%$ \\
6 & $4.14 \%$ & $2.01 \%$ & $0.13 \%$ \\
7 & $4.51 \%$ & $2.97 \%$ & $0.33 \%$ \\
8 & $7.73 \%$ & $8.86 \%$ & $0.59 \%$ \\
9 & $6.73 \%$ & $4.89 \%$ & $1.09 \%$ \\
10 & $8.19 \%$ & $7.61 \%$ & $2.84 \%$ \\
11 & $5.06 \%$ & $8.82 \%$ & $4.93 \%$ \\
12 & $30.13 \%$ & $41.79 \%$ & $40.45 \%$ \\
13 & $4.39 \%$ & $4.26 \%$ & $9.53 \%$ \\
14 & $5.89 \%$ & $4.85 \%$ & $10.95 \%$ \\
15 & $1.55 \%$ & $2.63 \%$ & $5.31 \%$ \\
16 & $6.02 \%$ & $5.73 \%$ & $14.08 \%$ \\
17 & $8.61 \%$ & $3.68 \%$ & $9.74 \%$ \\
$\mu$ & $11.12 \mathrm{yrs}$ & $11.48 \mathrm{yrs}$ & $13.33 \mathrm{yrs}$ \\
$\sigma$ & $3.49 \mathrm{yrs}$ & $2.62 \mathrm{yrs}$ & $2.11 \mathrm{yrs}$ \\
$\mathrm{n}$ & $2393 \mathrm{obs}$ & $2393 \mathrm{obs}$ & $2393 \mathrm{obs}$ \\
\hline
\end{tabular}


Table III: Regression Estimates of Childrens' Education as a Function of Parents' Education and Neighbors' Education

\begin{tabular}{||l||c|c|c|c|}
\hline VARIABLE & $(\mathbf{1})$ & $\mathbf{( 2 )}$ & $\mathbf{( 3 )}$ & $\mathbf{( 4 )}$ \\
\hline PARED & 0.379 & 0.413 & - & -0.262 \\
& $(0.022)$ & $(0.018)$ & - & $(0.165)$ \\
\hline NEIGHED & 0.127 & - & 0.127 & 0.525 \\
& $(0.044)$ & - & $(0.044)$ & $(0.450)$ \\
\hline MOMED & - & - & 0.204 & - \\
& - & - & $(0.025)$ & - \\
\hline DADED & - & - & 0.179 & - \\
& - & - & $(0.019)$ & - \\
\hline PARED & - & - & - & 0.012 \\
& - & - & - & $(0.007)$ \\
\hline NEIGHED & - & - & - & -0.028 \\
& - & - & - & $(0.016)$ \\
\hline P*NEIGHED & - & - & - & 0.032 \\
& - & - & - & $(0.0194)$ \\
\hline CONS & 7.51 & 8.53 & 7.45 & 7.554 \\
& $(0.417)$ & $(0.225)$ & $(0.425)$ & $(3.448)$ \\
\hline ADJ. R & 0.266 & 0.262 & 0.266 & 0.274 \\
\hline N & 1413 & 1413 & 1413 & 1413 \\
\hline \hline
\end{tabular}

Note.- standard errors are in parentheses. 
Table IV: Effect of Changes in Sorting on Steady-State Inequality, Intergenerational Correlation of Education, Inequality of Discounted Education, and Persistence of Inequality between Ethnic Groups* (Percentage increase over base case shown in parentheses.)

Note: Maintained assumptions are that $\alpha=0.379, \beta=0.127, \sigma_{\varepsilon}=1.74, \gamma=0, w_{m}=0.7$, and $w_{n}=0.5$.

\begin{tabular}{||l|l|l|l|l|l|l||}
\hline & $\rho_{\mathrm{m}}$ & $\rho_{\mathrm{n}}$ & $\sigma_{\infty}$ & $\rho_{\infty}\left(\mathrm{z}_{\mathrm{i}, \mathrm{z}} \mathrm{z}_{\mathrm{i}, t+1}\right)$ & $\sigma_{\mathrm{D}} *$ & $\theta$ \\
\hline Base case & $\begin{array}{l}0.6 \\
(-)\end{array}$ & $\begin{array}{l}0.2 \\
(-)\end{array}$ & $\begin{array}{l}1.874 \\
(-)\end{array}$ & $\begin{array}{l}0.329 \\
(-)\end{array}$ & $\begin{array}{l}2.242 \\
(-)\end{array}$ & $\begin{array}{l}0.432 \\
(-)\end{array}$ \\
\hline High Marital Sorting & $\begin{array}{l}0.8 \\
(33 \%)\end{array}$ & $\begin{array}{l}0.2 \\
(-)\end{array}$ & $\begin{array}{l}1.889 \\
(0.8 \%)\end{array}$ & $\begin{array}{l}0.367 \\
(11.5 \%)\end{array}$ & $\begin{array}{l}2.313 \\
(3.2 \%)\end{array}$ & $\begin{array}{l}0.444 \\
(2.6 \%)\end{array}$ \\
\hline $\begin{array}{l}\text { High Neighborhood } \\
\text { Sorting }\end{array}$ & $\begin{array}{l}0.6 \\
(-)\end{array}$ & $\begin{array}{l}0.4 \\
(100 \%)\end{array}$ & $\begin{array}{l}1.899 \\
(1.3 \%)\end{array}$ & $\begin{array}{l}0.354 \\
(7.7 \%)\end{array}$ & $\begin{array}{l}2.307 \\
(2.9 \%)\end{array}$ & $\begin{array}{l}0.445 \\
(2.9 \%)\end{array}$ \\
\hline High General Sorting & $\begin{array}{l}0.8 \\
(33 \%)\end{array}$ & $\begin{array}{l}0.4 \\
(100 \%)\end{array}$ & $\begin{array}{l}1.915 \\
(2.2 \%)\end{array}$ & $\begin{array}{l}0.392 \\
(19.3 \%)\end{array}$ & $\begin{array}{l}2.382 \\
(6.2 \%)\end{array}$ & $\begin{array}{l}0.457 \\
(5.6 \%)\end{array}$ \\
\hline
\end{tabular}




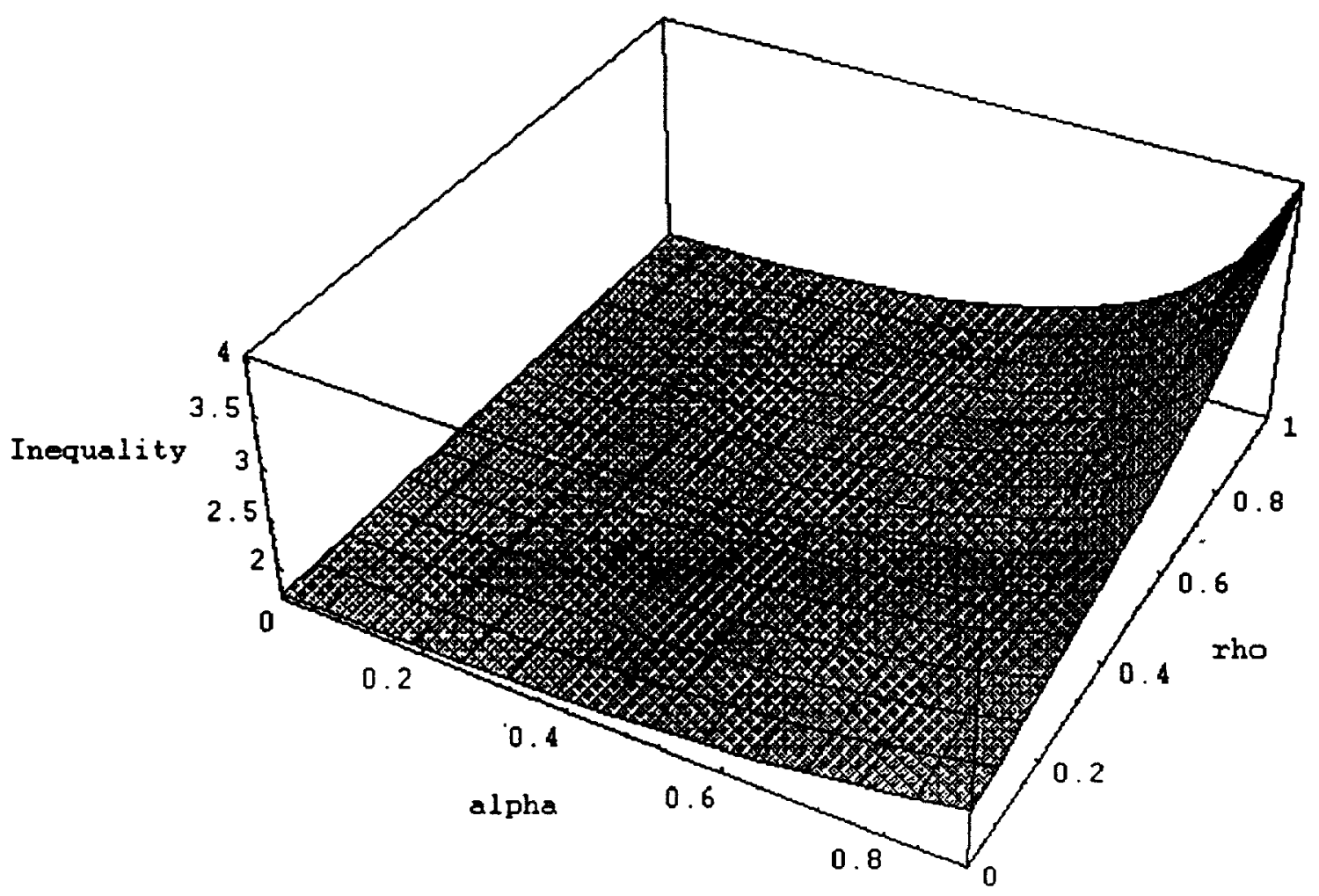

Figure 1.

Inequality as a function of $\alpha$ and $\rho$ 